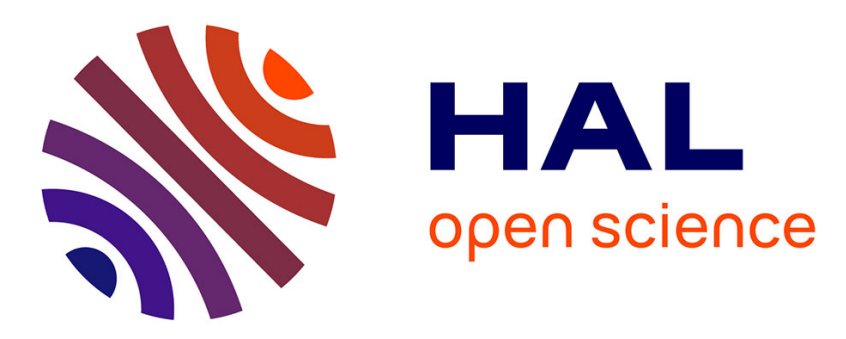

\title{
Solution Structure of Alo-3: A New Knottin-Type Antifungal Peptide from the Insect Acrocinus longimanus
}

F. Barbault, C. Landon, M Guenneugues, J-P Meyer, V Schott, J-L Dimarcq, Francoise Vovelle

\section{- To cite this version:}

F. Barbault, C. Landon, M Guenneugues, J-P Meyer, V Schott, et al.. Solution Structure of Alo-3: A New Knottin-Type Antifungal Peptide from the Insect Acrocinus longimanus. Biochemistry, 2003, 42 (49), pp.14434 - 14442. 10.1021/bi035400o . hal-02422703

\section{HAL Id: hal-02422703 https://hal.science/hal-02422703}

Submitted on 22 Dec 2019

HAL is a multi-disciplinary open access archive for the deposit and dissemination of scientific research documents, whether they are published or not. The documents may come from teaching and research institutions in France or abroad, or from public or private research centers.
L'archive ouverte pluridisciplinaire HAL, est destinée au dépôt et à la diffusion de documents scientifiques de niveau recherche, publiés ou non, émanant des établissements d'enseignement et de recherche français ou étrangers, des laboratoires publics ou privés. 


\title{
Solution Structure of Alo-3: A New Knottin-Type Antifungal Peptide from the Insect Acrocinus longimanus
}

\author{
F. Barbault ${ }^{1,2}$, C. Landon ${ }^{1}$, M. Guenneugues ${ }^{3}$, J-P. Meyer ${ }^{3}$, V. Schott ${ }^{3}$, J-L. Dimarcq ${ }^{3}$ and F. Vovelle ${ }^{1 *}$ \\ 1. Centre de Biophysique Moleculaire, CNRS UPR 4301, rue C. Sadron, 45071 Orleans Cedex 02, France \\ 2. Present address: Laboratoire ITODYS, 1 rue Guy de la Brosse, 75005 Paris, France \\ 3. ENTOMED S.A., rue Tobias Stimmer, 67400 Illkirch, France \\ * Phone: +33 2382555 74; Fax: +332386315 17; E-mail: vovelle@cnrs.orleans.fr
}

Original reference:

F. Barbault, C. Landon, M. Guenneugues, J-P. Meyer, V. Schott, J-L. Dimarcq, F. Vovelle Biochemistry 2003 (42) 14434-42

\begin{abstract}
Insect peptides are key elements of the innate immunity against bacteria and fungi. These molecules offer remarkable properties: high efficacy, a low probability of resistance, limited toxicity, and immunogenicity. In this context, we are investigating several classes of peptides, and we have been successful in identifying biologically important classes of peptides and small molecules that will provide a stream of drug candidates for treating severe, life-threatening, hospital-acquired infections and other pathologies of high medical need. Recently, we have isolated a new class of antifungal peptides from the coleopteran Acrocinus longimanus. Three homologous peptides, Alo-1, Alo-2, and Alo-3, with sequence identity above $80 \%$ and active against the Candida glabrata yeast strain were identified. Alo-3 displayed the highest activity against Candida glabrata and was thus chosen for structure determination using NMR spectroscopy and molecular modeling. Alo-3 contains six cysteine residues forming three disulfide bridges. The pairing of the cysteines was assessed using ambiguous disulfide restraints within the ARIA software, allowing us to establish that Alo3 belongs to the inhibitor cystine-knot family. It exhibits all the structural features characteristic of the knottin fold, namely, a triple-stranded antiparallel â-sheet with a long flexible loop connecting the first strand to the second strand and a series of turns. To our knowledge, Alo-3 is the first peptide from insects with antimicrobial activity adopting the knottin fold. Alo-3 shows a level of activity significantly higher against C. glabrata than Alo-1 or Alo-2. It has no negatively charged residues and displays on its surface a cationic pole that may account for its antifungal activity. This finding is validated by the comparison of the structure of Alo-3 with the structure of other structurally related peptides from othersources also showing antifungal activity.
\end{abstract}

\section{Introduction}

The increasing resistance of pathogenic microorganisms to conventional antibiotics has stimulated the development of new therapeutic agents. In particular, with the advent of new chemotherapeutic drugs and the increasing number of immunocompromised patients, fungal infections have emerged as a critical issue in the compromised host. Fungi cause a large variety of diseases in humans such as candidiasis and aspergillosis. Invasive candidiasis are widespread infections on individuals with reduced function of the immunity system. The genus of the yeast Candida includes around 150 species, among which Candida albicans is the most abundant and significant species, causing approximately $50 \%$ of invasive candidiasis. However, importantly, there has been a recent increase in infections due to non-albicans Candida rare species, such as C. glabrata ( $15 \%$ of invasive candidasis) (1). Unfortunately, most C. albicans and C. glabrata strains have developed resistance to fluconazole and itraconazole, two drugs widely used for treatments of candidiasis (2), so that the need for new agents has become critical given the low efficiency and the toxicity of these standard treatments. Recently, antimicrobial peptides have emerged as a possible solution to this health problem: these peptides have a broad spectrum of antimicrobial activity with a low mammalian cell cytotoxicity, making them good candidates for therapeutic developments.

Antimicrobial peptides constitute an important component of the innate immunity against bacterial and fungal infections. In particular, peptides with antifungal activity have been isolated from mammals, insects, plants, amphibians, and microorganisms (3). These peptides are usually cationic with arginine as the predominant cationic residue. Most of them display an amphipathic character, and their mechanisms of action involve the disruption of the cell membranes. A large structural diversity occurs in the collection of antifungal peptides, but peptides including three or more disulfide bonds constitute the largest group in insects, mammals, and plants: $\alpha$ and $\beta$ mammal defensins containing three disulfide bridges (4) possess a three-stranded antiparallel â-sheet fold. Antifungal defensins from insects or plants (three or four disulfide bridges) display a CS $\alpha \beta$ fold consisting of a single $\alpha$-helix connected to a highly twisted antiparallel $\beta$-sheet by two conserved disulfide bridges (5). Thionins from plants (four or sometimes three disulfide bridges) resemble the Greek letter $\Gamma$ with a long arm formed by two $\alpha$-helices and a short one formed by a two-stranded antiparallel $\beta$-sheet (6). Ace-AMP1 from onion seeds (7) (four disulfide bridges) displays an original fold including four $\alpha$-helices wound in a righthanded superhelix. The hevein and hevein-like peptide (four disulfide bridges) fold includes a three-stranded $\beta$-sheet as well as an $\alpha$-helix turn linking the second strand and the third strand (8). Another structural motif has been identified in plant peptides (9-11), namely, the knottin fold characterized by a triple-stranded $\beta$-sheet and the inhibitor cystineknot (ICK) arrangement of the three disulfide bonds (12-14). All these particular folds, stabilized by the numerous hydrogen bonds of the secondary structure elements and by several disulfide linkages, are possible ways to overcome the problem of stability of small proteins and to enhance their resistance to protease cleavage.

Insects constitute an important source of antimicrobial peptides (15). Among these peptides, several are active only on fungal or/and yeast strains. Drosomycin (16), heliomicin (17), and termicin (18) are 
cysteine-rich peptides adopting the typical fold of insect defensins (19-21). Thanatin (22) is a short peptide with a â-sheet structure (23) that is also active against bacteria. Recently, we have isolated from the coleopteran Acrocinus longimanus a new class of antifungal peptides. These peptides, constitutively expressed as Alo-1, Alo-2, and Alo-3, are active against C. albicans and C. glabrata at low concentrations. They display sequence similarities with four other antifungal peptides isolated from plants (Figure 2): Me_AMP1 from Mesenbryanthenum crystallinum (24), Mj_AMP1 and Mj_AMP2 from Mirabilis jalapa (25), and PAFP-S from the seeds of Phytolacca americana (26). All these peptides show a knottin-like cysteine motif in their sequence, and the recently determined NMR structure of PAFP-S (11) confirms that this peptide, and most probably the three others, adopts a knottin fold.

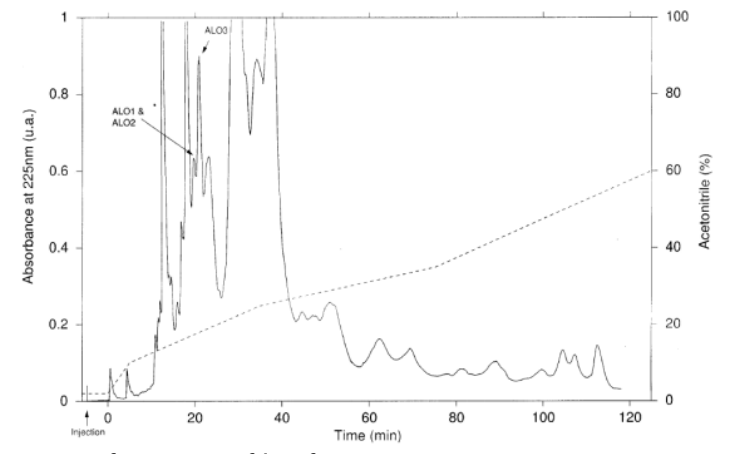

Figure 1: Purification profile of ALO3.

A

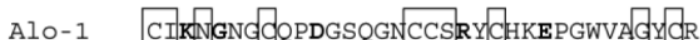
Alo-2 CIANRNG dQPDGSQGNCCS GYCHKEPGWVA GY OR Me AMP1 CT $\mathrm{Mj}^{-}$-AMP1 CIGNGGR QNENVGPPYCCSGFCLRQPGQGYGY $q K N R \quad 47 \%$ $\mathrm{Mj}$ AMP2 CIGNGGR dNENVGPPYCCSGFCLRQPNQGYGVORNR $44 \%$ PAFP-S CIKNGGRGNASAGPPYCCSSYCFQIAGQSYGVGKNR $36 \%$ B

\section{AlO-3 --CIKNGNGCOPNGSOGNCCSGYCHKOPGWVAGYCRRK \\ PAFPS AGCIKNGGRCNASAGPPYCCSSYCFQIAGQSYGVCKNR \\ AlO-3 - -CIKNGNGCQPNGSQGNCCSGY-CHKQPGWVAGYCRRK \\ ACTX KCLAEA-ADCSPWSGD-SCCKPYLCSCIFF-Y \\ AlO-3 - - - CI KNGNGCQPNGSQG-N- - CCSG-YCHKQPGWV-AGYCRRK \\ TACh YSRCQLQG-FNCVVRSYGLPTIPCCRGLTCRSYFPGSTYGRCQRY}

Figure 2: (A) Sequence alignment of Alo-3 with Alo-2, Alo-3, and Me_AMP1 from M. crystallum (24), Mj_AMP1 and Mj_AMP2 from M. jalapa (62), and PAFP-S from P. americana (26). In bold are the residues differing among Alo-1, Alo-2, and Alo-3. The percentages of identity of each peptide with Alo-3 are indicated. (B) Structural alignment of Alo-3 with PAFPS (PAFP-S) (11), with ACTX (ACTXHi:OB4219) (55), and with Tach (tachystatin A) (57). In a best fitted superposition of the structures, two residues are considered as structurally aligned when their distance is less than $2 \AA$. Gray background: structurally aligned residues. Underlined residues: secondary structure elements.

We have determined the three-dimensional structure of Alo-3, the peptide of the Alo family displaying the highest efficacy against $\mathrm{C}$. glabrata, using NMR spectroscopy and molecular modeling techniques. Alo-3 exhibits all the structural features characteristic of the knottin fold and to our knowledge is the first peptide isolated from insect hemolymph showing antimicrobial activity that adopts this particular fold. On the basis of sequence comparisons with Alo1 and Alo-2 showing a level of activity significantly lower against $C$. glabrata than Alo-3, and on the basis of structural comparisons with structurally related peptides, we were able to delineate a cationic pole that may account for the antifungal activity of Alo-3.

\section{Experimental Procedures}

Insect Immunization and Hemolymph Collection

Mature larvae of the coleoptera A. Iongimanus (Cerambicidae family) were individually immunized by one injection of $20 \mu \mathrm{L}$ of a PBS solution containing the Gram-positive bacteria Micrococcus luteus and Staphylococcus aureus, the Gram-negative bacteria Pseudomonas aeruginosa, the yeast $C$. albicans, and the filamentous fungus Aspergillus fumigatus. The bacteria were prepared from overnight cultures at $37^{\circ} \mathrm{C}$ in Luria-Bretani medium. The yeast was prepared from overnight cultures realized at $30^{\circ} \mathrm{C}$ in Sabouraud medium, whereas the fungal spores were taken from a stock frozen at $-80^{\circ} \mathrm{C}$. After $24 \mathrm{~h}$, the insects were chilled on a bed of ice, and hemolymph was collected (about $1.5 \mathrm{~mL} / \mathrm{larva}$ ) by sectioning an abdominal appendix and gently squeezing the abdomen. The hemolymph was pooled in ice-cold polypropylene tubes containing apoprotine as a protease inhibitor $(20 \mu \mathrm{g} / \mathrm{mL}$, final concentration) and phenylthiourea as a melanization inhibitor (40 $\mu \mathrm{M}$, final concentration). Hemolymph $(30 \mathrm{~mL})$ was centrifuged for 1 min at $4{ }^{\circ} \mathrm{C}$ at $8000 \mathrm{rpm}$. The resulting supernatant was then centrifuged for $20 \mathrm{~min}$ at $4{ }^{\circ} \mathrm{C}$ at $12000 \mathrm{rpm}$. Cell-free hemolymph was frozen at $-80^{\circ} \mathrm{C}$ until use.

\section{Purification Procedure}

A $5 \mathrm{~mL}$ sample of the hemolymph was acidified to $\mathrm{pH} 3$ with water containing 1\% TFA (trifluoroacetic acid). Extraction was performed by gentle shaking for $30 \mathrm{~min}$ on an ice bath. After centrifugation at $10000 \mathrm{~g}$ at $4{ }^{\circ} \mathrm{C}$ for $30 \mathrm{~min}$, the supernatant was loaded onto a $5 \mathrm{~g}$ C18 cartridge (Sep-Pak from Waters) equilibrated with water containing $0.05 \%$ TFA. A washing step with water/0.05\% TFA was used to eliminate salts and other hydrophilic material. Peptides of interest were then eluted with $60 \%$ acetonitrile in water, with $0.05 \%$ TFA. The latter fraction was dried in a vacuum centrifuge (SpeedVac, Savant) and reconstituted with water $/ 0.05 \%$ TFA before purification. This fraction was subjected to HPLC purification on a preparative C8 column (Aquapore RP-300 from Brownlee, 220x4.6 $\mathrm{mm}, 300 \AA$ ). Elution was performed with a linear gradient of acetonitrile/ $0.05 \%$ TFA against water/0.05\% TFA, from $2 \%$ to $10 \%$ in $5 \mathrm{~min}$, then from $10 \%$ to $25 \%$ in $30 \mathrm{~min}$, then from $25 \%$ to $35 \%$ in 40 $\mathrm{min}$, and then from $35 \%$ to $60 \%$ in $50 \mathrm{~min}$, for a total run time of 125 min, at a constant flow of $2.5 \mathrm{~mL} / \mathrm{min}$. Fractions were manually collected according to UV absorbance at $225 \mathrm{~nm}$. All fractions were then dried, reconstituted in MilliQ water, and tested for activity against $\mathrm{C}$. albicans, as described by Lamberty et al. (17). In a second step of purification, the fraction with antifungal activity containing the peptide of interest (eluting with $18 \%$ acetonitrile) was further purified on an analytical C8 column (Aquapore RP-300 from Brownlee, $2204.6 \mathrm{~mm}, 300 \AA$ ) . Elution was performed with a biphasic linear gradient of acetonitrile/ $0.05 \%$ TFA against water $/ 0.05 \%$ TFA, from $1 \%$ to $14 \%$ in $10 \mathrm{~min}$ and then from $14 \%$ to $22 \%$ in $45 \mathrm{~min}$ at a constant flow of $0.8 \mathrm{~mL} / \mathrm{min}$. Fractions were treated as above. In the final step of purification the fraction with antifungal activity was purified to homogeneity on a narrowbore $\mathrm{C} 18$ column (Delta Pak HPI from Waters, $150 \times 2 \mathrm{~mm}, 300 \AA$ ). Elution was performed with a biphasic linear gradient of acetonitrile/0.05\% TFA against water/0.05\% TFA, from $2 \%$ to $11 \%$ in $5 \mathrm{~min}$ and then from $11 \%$ to $19 \%$ in 50 min at a constant flow of $0.2 \mathrm{~mL} / \mathrm{min}$.

\section{Structural Characterization}

Peptide purity was assessed by MALDI-TOF mass spectral analysis, as described by Uttenweiler-Joseph et al. (27), on a Bruker Biflex (Bremen, Germany) instrument. Reduction of disulfide bridges followed by S-pyridylethylation was performed (28). Sequencing of the reduced S-pyridylethylated peptide was performed by N-terminal amino acid Edman degradation on a pulse liquid automatic sequencer ( $A B I$ 473A from Applied Biosystem). Confirmation of the $C$-terminal sequence was obtained by sequencing after enzymatic cleavage (see ref 17). 


\section{Peptide Resupply}

Alo-1, -2 , and -3 were obtained in milligram quantities via chemical synthesis from Altergen, a Schiltigheim, France, based company. The purity and integrity of the material were checked by analytical HPLC and MALDI-TOF mass spectroscopy; the purification profile is presented in Figure 1. Activity against the Candida strains was also assessed.

\section{Antimicrobial Assays}

The strains C. albicans IHEM 8060 and C. glabrata "patient 1" used in this study were generous gifts from $\mathrm{H}$. Koenig (Hôpital civil de Strasbourg, France). The strains C. albicans ATCC 36082 and C. glabrata ATCC 90030 were obtained from the American Type Culture Collection (Manassas, VA). The antimicrobial properties of the peptides against the yeasts $C$. albicans and $C$. glabrata were carried out following a growth inhibition assay in liquid medium in 96 -well microplates. The MIC determination against yeast was performed in Sabouraud medium. The final inoculum was of 2.5103 yeasts $/ \mathrm{mL}$. The microdilution trays were incubated at $30{ }^{\circ} \mathrm{C}$ for 24 and $48 \mathrm{~h}$. Activity was determined for concentrations ranging between 0.125 and $64 \mu \mathrm{g} / \mathrm{mL}$. The percentage of growth (\% growth) was deduced from the absorbance (OD) at $600 \mathrm{~nm}$ after $48 \mathrm{~h}$ of incubation using the following relationship:

$$
\% \text { growth }=\frac{O D(\text { well to test })-O D(\text { medium })}{O D(\text { well without peptide })-O D(\text { medium })} \times 100
$$

The MIC was determined as the value for which the \% growth was below $10 \%$, corresponding to a classical MIC ) 0 if visual scores are taken. NMR Experiments. All $1 \mathrm{H}$ NMR spectra were recorded on a VARIAN INOVA NMR spectrometer equipped with a $z$-axis gradient field and operating at a proton frequency of $600 \mathrm{MHz}$. The NMR sample was prepared by dissolving $3 \mathrm{mg}$ of Alo-3 in sodium acetate buffer ( $40 \mathrm{mM}, \mathrm{pH} 5.2)$ in $90 \% \mathrm{H} 20,10 \% \mathrm{D} 20$ at a final concentration of $1.2 \mathrm{mM}$. To solve assignment ambiguities, 1H DQF-COSY (29), TOCSY (30), and NOESY (31) spectra were recorded at two temperatures (293 and $303 \mathrm{~K}$ ). NOESY spectra were obtained using mixing times of 120 and 300 ms and TOCSY spectra with a mixing time of $80 \mathrm{~ms}$. The water signal was suppressed using the WATERGATE pulse sequence (32). To identify the exchange rate of backbone amide protons, the sample was lyophilized and quickly dissolved in D20. The exchange kinetics experiments were then monitored from 1D spectra at different times and from short TOCSY spectra. All NMR data were processed with NMRpipe and NMRdraw software (33) and analyzed with NMRview (34). The standard strategy of Wüthrich (35) was used to elucidate the complete proton NMR assignment of Alo-3.

\section{Structure Calculations}

The cross-peak intensities on the NOESY spectrum recorded with a $120 \mathrm{~ms}$ mixing time were integrated and partially assigned within NMRview (34). These NOEs, along with a table of chemical shifts, were used as input to ARIA 1.1 (36) implemented in CNS 1.1 (37). The calculations were performed starting from random templates, using the standard parameters of ARIA. ARIA is a method combining an iterative NOE interpretation scheme with a dynamical assignment of ambiguous NOE cross-peaks treated as the sum of contributions from all possible assignments. A large number of NOEs were calibrated and assigned automatically during the structure calculation by ARIA. The procedure of assignment/refinement was repeated iteratively. At each step, the new assignments proposed by ARIA were carefully checked manually and introduced (or not) into the subsequent run. Rejected restraints and residual NOE violations were analyzed, and the assignments were corrected if needed. In the final iteration, the 100 structures with the lowest energy were further the extended consensus sequence $\mathrm{CX}_{3-7} \mathrm{CX}_{3-8} \mathrm{CX}_{0-7} \mathrm{CX}_{1-4} \mathrm{CX}_{4-13} \mathrm{C}$ found for polypeptides from diverse sources adopting the ICK motif (14). refined by molecular dynamics calculations in explicit solvent to remove artifacts (38).

The structures were displayed and analyzed using the MOLMOL (version 2K.1) software (39). The electrostatic potentials were calculated by solving the Poisson-Boltzmann equations with DELPHI algorithms (40) included in MOLMOL. The lipophilic/hydrophilic properties of molecules were appreciated by coloring the residues at the molecular surface according to a hydrophobic scale defined by Eisenberg (41).

\section{Results}

\section{Antimicrobial Assays}

Antifungal activities of Alo peptides are given in Table 1. Alo-1 is poorly active and Alo-2 not active against Candida species. On the other hand, Alo-3 displays some potency with $\mathrm{MIC}=0$ values below those exhibited by fluconazole against $C$. albicans ( 16 vs $>64$ $\mu \mathrm{g} / \mathrm{mL}$ ) and C. glabrata (8 vs $64 \mu \mathrm{g} / \mathrm{mL}$ ).

Table 1: Antifungal Activities of Alo-1, Alo-2 and Alo-3 peptides.

\begin{tabular}{lcccc}
\hline & \multicolumn{4}{c}{ MIC $(\mu \mathrm{g} / \mathrm{mL})$} \\
\cline { 2 - 5 } \multicolumn{1}{c}{ drug } & $\begin{array}{c}\text { C. glabrata } \\
\text { patient 1 }\end{array}$ & $\begin{array}{c}\text { C. glabrata } \\
\text { ATCC 90030 }\end{array}$ & C. albicans & C. albicans \\
\hline Alo-1 & $>64$ & nd & 64 & nd \\
Alo-2 & $>64$ & nd & $>64$ & nd \\
Alo-3 & 8 & 16 & 16 & 8 \\
fluconazole & 64 & 64 & $>64$ & 1 \\
ampho B & 0.12 & 0.12 & 0.06 & 0.12 \\
\hline
\end{tabular}

\section{Sequential Assignment and Secondary Structure}

The complete assignment of the proton NMR resonances of Alo-3 was obtained from the $1 \mathrm{H}$ DQF-COSY, TOCSY, and NOESY spectra using the standard strategy of Wüthrich (35). The proton resonances were quasi-totally-assigned except for some $\eta(\mathrm{NH} 2)$ resonances of arginine residues, $\gamma(\mathrm{OH})$ resonances of serines, and $\zeta(\mathrm{OH})$ resonances of tyrosines. The table containing the proton chemical shifts of Alo-3 is available as Supporting Information.

Low-field-shifted HR chemical shifts and characteristic $\mathrm{H} \alpha(\mathrm{i})-\mathrm{H} \alpha$ (j), $\mathrm{NH}(\mathrm{i})-\mathrm{NH}(\mathrm{j})$ and $\mathrm{H \alpha}$ (i)-NH(j) connectivities on the NOESY map provided evidence for the presence of a triple-stranded antiparallel $\beta$-sheet involving residues 6-9, 21-24, and 31-34 (Figure 3). The presence of medium range NOEs in the rest of the structure suggests that it consists mainly of loops and turns. Strong $\mathrm{H} \alpha$ (i)$\mathrm{H} \delta(\mathrm{i}+1)$ and $\mathrm{NH}(\mathrm{i})-\mathrm{H} \delta(\mathrm{i}+1)$ NOE cross-peaks for Gln9-Pro10 and GIn25-Pro26 indicate the presence of trans peptide bonds for the two prolines.

A set of 800 structures was calculated using the standard ARIA protocol and an ensemble of 490 NOE restraints, mostly derived from intraresidue and sequential NOEs as well as from unequivocal long-range NOEs. A set of 130 structures showing no NOE violation larger than $0.3 \AA$ was selected to establish the disulfide pairing. In this respect, we have considered that a disulfide bridge was formed when the S $\gamma$-S $\gamma$ distance was less than $3 \AA$. Using this criterion, the Cys1-Cys 18 disulfide bridge occurs on $86 \%$ of the selected structures while the Cys8-Cys 22 one is formed on $74 \%$ of the structures. The remaining Cys17-Cys33 disulfide bridge was indirectly deduced as the only one possible, although its occurrence is only $15 \%$, probably due to the poor number of NOE correlations in this region. Therefore, the cysteine bonding pattern is identical to the ICK pairing: Cys(I-IV), Cys(II-V), and Cys(III-VI) in agreement with 


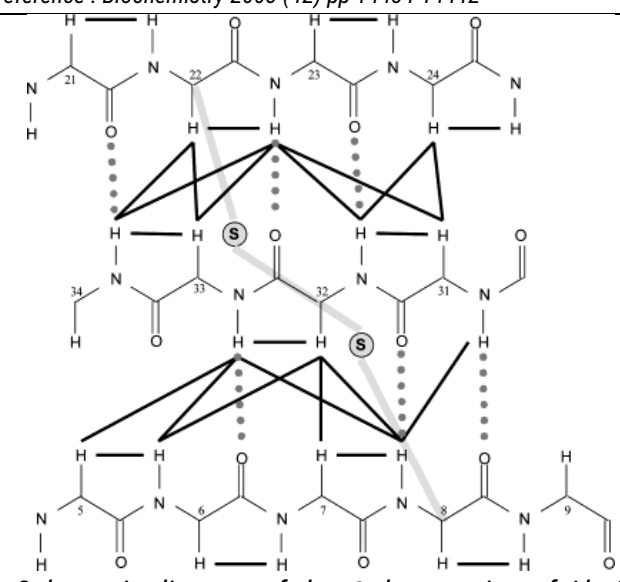

Figure 3: Schematic diagram of the $\beta$-sheet region of Alo-3 and NOE connectivities (black lines). Dotted lines represent the hydrogen bonds deduced from the $1 \mathrm{H} / 2 \mathrm{H}$ exchange data.

\section{Identification of the Disulfide Bonds}

The mass spectrometry experiment clearly indicates that the six cysteines of Alo-3 sequence are involved in three disulfide bridges. Any attempt to identify the disulfide bridges from $\mathrm{H} \alpha-\mathrm{H} \beta$ and $\mathrm{H} \beta-\mathrm{H} \beta$ NOE correlations between cysteines were unsuccessful due to frequent cross-peak overlaps and did not permit a satisfactory solution to be obtained. To solve this problem, we used a more reliable approach, based on the concept of ambiguous distance restraints initially introduced by Nilges (42) for symmetric dimers and developed for proteins with unknown disulfide bridge pairing (43). Ambiguous constraints were introduced between each specific cysteine $S \gamma$ atom and the $S \gamma$ atoms of all other cysteine residues, the SUM option (42) was used for averaging all ambiguous restraints, and the van der Waals radius of the cysteine $S \gamma$ atoms was reduced ( $2 \AA$ ) to allow close contacts between sulfur atoms forming disulfide bonds.

\section{Structure Calculations}

In the following ARIA runs, the $S \gamma-S \gamma$ covalent bonds between the paired cysteines were included in the topology files. After nine simulated annealing iterations of ARIA, all NOE peaks of the $120 \mathrm{~ms}$ NOESY map were assigned and 100 structures of Alo-3 were refined by molecular dynamics in an explicit solvent environment. Finally, the 10 structures with the lowest potential energies and showing no experimental distance violation larger than $0.3 \AA$ were selected for analysis. The final data file (Table 2), comprising 533 distance restraints (15 restraints per residue, on average), allowed determination of the 3D structure with a good precision. A summary of the pairwise RMSDs for Alo-3 is given in Table 2. The Ramachandran plot exhibits $90 \%$ of the $(\phi, \psi)$ angles of the 20 converged structures in the most favored regions and additional allowed regions according to the PROCHECK software nomenclature (44). The residues in the generously and disallowed region (10\%) are located in loop L1 (Pro10-Gly20).

Global Fold
A sausage representation of the backbone atoms of the 10 best converged structures of Alo-3 is shown in Figure 4. The main structural element of Alo-3 is an antiparallel triple-stranded â-sheet consisting of strand B1 (Asn6-Gln9) hydrogen bonded to strand B3 (Gly31-Arg34), which in turn is hydrogen bonded to strand B2 (Tyr21Lys24). All the canonical hydrogen bonds of the â-sheet are formed, in agreement with the $1 \mathrm{H} / 2 \mathrm{H}$ exchange experiments. This part of the structure is well-defined with low pairwise RMS deviations $(0.70+/$ $0.14 \AA$ for the backbone atoms of the $\beta$-sheet). A first turn [T1 (Cys1Gly5)] precedes the first strand of the $\beta$-sheet (B1) and a loop [L1 (Pro10-Gly20)] connects B1 and B2. This loop is 11 residues long and shows some variability, probably due to a lack of NOEs in this region; the RMS deviation for the backbone atoms is 1.71 ( $0.38 \AA$. The second (B2) and third (B3) strands of the â-sheet are linked by a long turn [T2 (GIn25-Ala30)]. The first disulfide bridge (Cys1-Cys18) links the N-terminal extremity to the L1 loop; the second one (Cys8Cys22) connects the two parallel nonadjacent strands B1 and B2. The last one (Cys17-Cys33) linking the L1 loop to B3 penetrates the ring formed by the backbone and the two other disulfide bridges, forming the ICK motif.

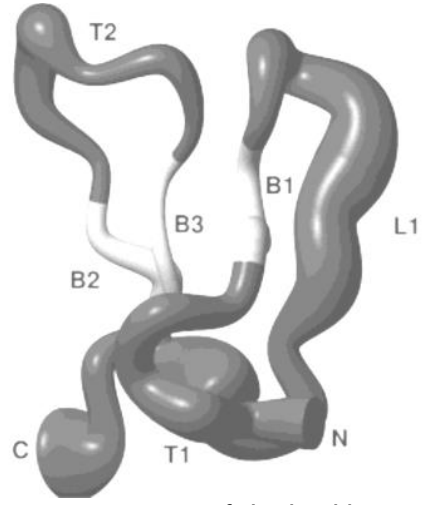

Figure 4: Sausage representation of the backbone of the 10 selected structures of Alo-3. The radius of the sausage is proportional to the RMSD on the coordinates of the backbone atoms of the 10 structures. The three strands $(B 1, B 2, B 3)$ of the sheet are in light gray and the loops and turns in black.

\section{Electrostatic and Hydrophobicity Analysis}

The isopotential contours at $+/-1$ e $\AA^{-1}$ represented in Figure 5 indicate, as expected from the net charge of Alo-3 $(+6)$, that the contours are mainly electropositive. There is a large electropositive face around the T1 turn (Lys3), B2 (His23 and Lys24), the end of B3 (Arg34), and the C-terminal extremity (Arg35 and Lys36). The opposite face, consisting of the beginning of the L1 loop and of the T2 turn, does not lead to noticeable features. The distribution of hydrophobic and hydrophilic residues at the molecular surface of Alo-3 (Figure 5, bottom) shows that the peptide surface is essentially hydrophilic with a predominance of green and blue residues. The only noticeable hydrophobic patch is formed in the T2 turn by Trp28, Val29, and Ala30.

Table2: NOE data and structural statistics.

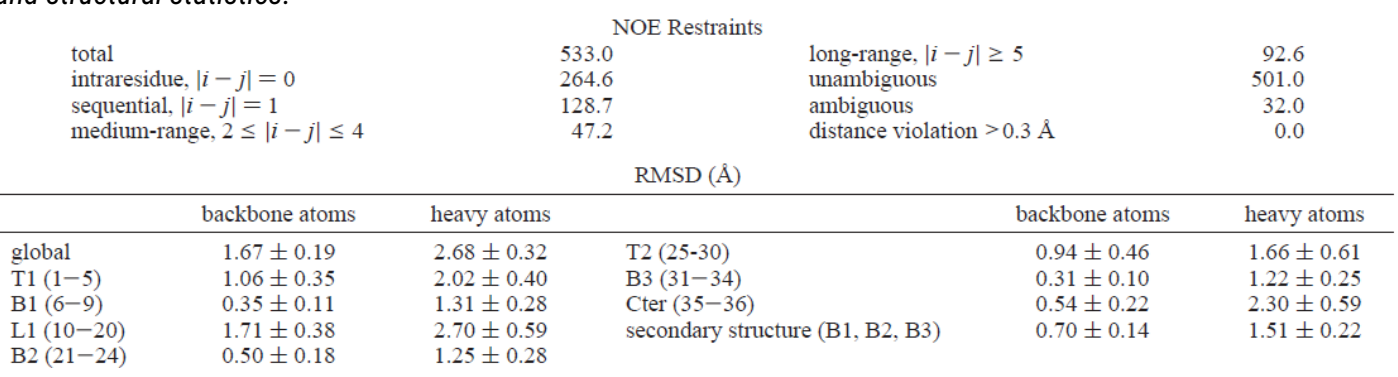




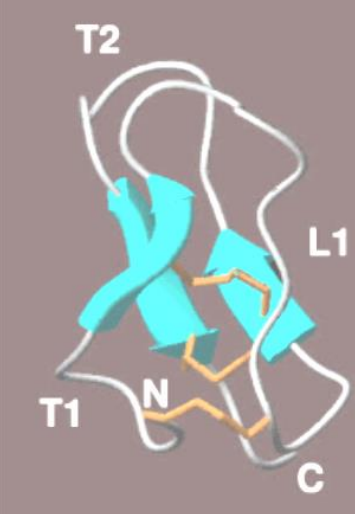

ALO3
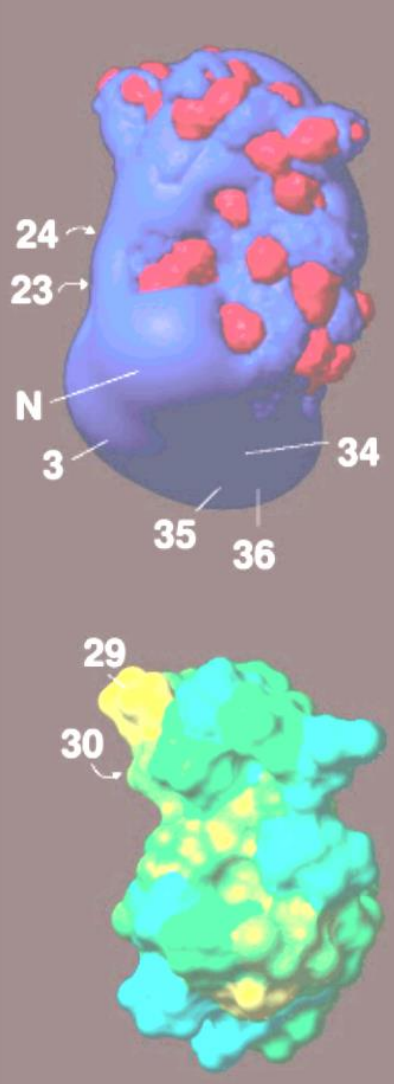

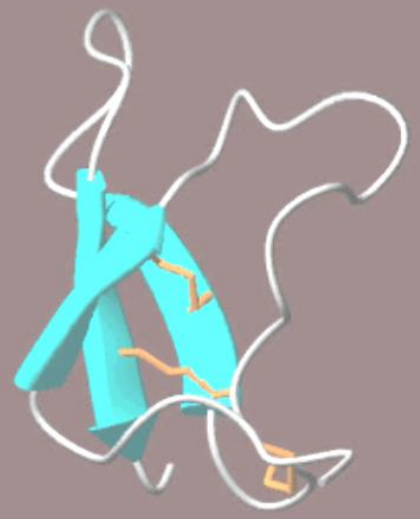

Tachystatin-A
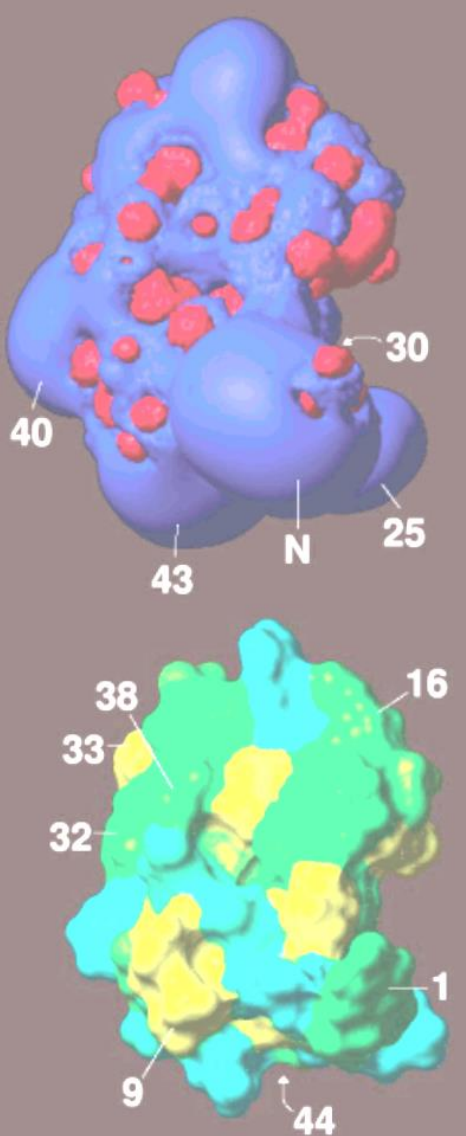

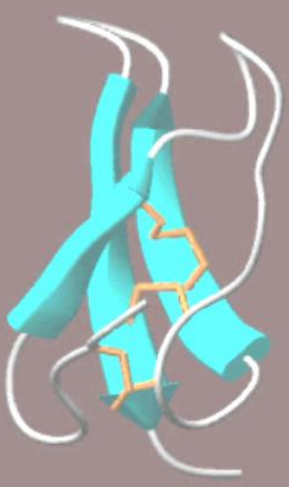

PAFP-S
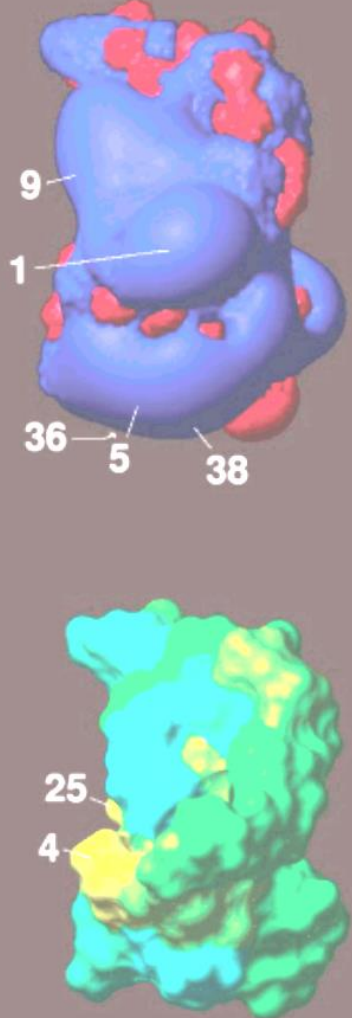

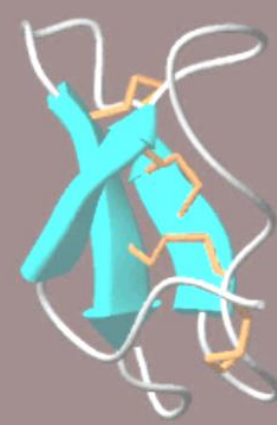

ACTX

Figure 5: (Top) Global fold of Alo-3, tachystatine A, PAFP-S, and ACTX. (Middle) Electrostatic contours at +1 e $\AA^{-1}$ (red) and -1 e $\AA^{-1}$ (blue) for the four molecules in the same orientation and in the same order. (Bottom) Distribution of hydrophobic and hydrophilic residues at the surface of the four molecules according to the hydrophobic scale of Eisenberg (41): yellow (Val, Leu, Ile, Trp), green (Cys, Ala, Gly, Tyr, Pro, Thr, Ser, Asn, Gln), blue (His, Asp, Asn, Glu, Gln, Arg, Lys). This figure was drawn with MOLMOL (39).

\section{Discussion}

We have determined the three-dimensional structure of the antifungal peptide Alo-3. The use of ambiguous inter-sulfur restraints within the ARIA software allowed us to assign the disulfide connectivities of the six cysteines. The dominant structural features of the Alo-3 scaffold are an antiparallel triple-stranded âsheet and three disulfide linkages forming the so-called inhibitor cystine-knot or knottin fold (13). Therefore, the structure of Alo-3 constitutes a new type of scaffold for cysteine-rich peptides from insects with antimicrobial activity.
We have compared the sequence of Alo-3 to the two other antifungal peptides isolated from $A$. longimanus. The primary structures of these two peptides, Alo- 1 and Alo-2, are very close to the Alo-3 sequence, but their levels of activity against the yeasts $C$. albicans and C. glabrata are significantly different (Table 1$)$. In particular, Alo3 is efficient against C. glabrata (MIC ) $8 \mathrm{ig} / \mathrm{mL}$ ), whereas Alo-1 or Alo-2 is inactive (MIC $>64 \mu \mathrm{g} / \mathrm{mL}$ ). The sequence of Alo-1 includes five positive residues (Lys3, Arg20, His23, Lys24, Arg34) and two negative ones (Asp11, Glu25) (Figure 2).Alo-2 presents four positively charged residues (Arg5, His23, Lys24, Arg34) and two negative ones (Asp11, Glu25). Finally, Alo-3 is the most cationic of the group, with no negatively charged residues and with, compared to Alo-2, two additional positively charged residues (Arg35 and Lys36) forming a C-terminal extension. The positions of the residues differing in the three peptides (in bold in Figure 2) are depicted on 
the three-dimensional structure of Alo-3 (Figure 6). Residues 3, 5, 20, 35 , and 36 belong to the electropositive face of Alo-3. The electropositivity of this pole is considerably increased in Alo-3 compared to Alo-1 and Alo-2. We can therefore correlate the augmentation of the positive charge of this region with an improvement of the antifungal activity of the molecule against $\mathrm{C}$. glabrata. In the same way, residues 11 and 25 are negatively charged residues in Alo-2 and Alo-1 (Asp11 and Glu25) and polar residues (Asn11 and GIn25) in Alo-3. This confers a more neutral character to the other pole of the Alo-3 molecule. The balance between the electropositive face and the neutral region seems therefore to be an important feature for the activity of these molecules.

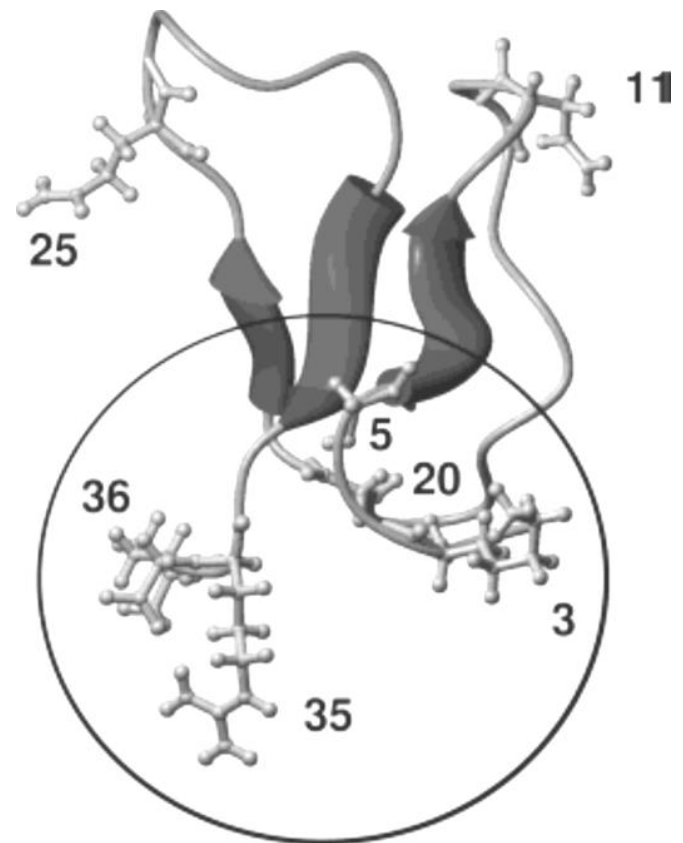

Figure 6: Representation of the global fold of Alo-3. The side chains of the residues differing among Alo-1, Alo-2, and Alo-3 are represented. The cationic pole is circled.

The inhibitor cystine-knot motif, initially reported for the potato inhibitor carboxypeptidase A (45), is found for a variety of peptides (typically less than 40 residues in length) from plants, crabs, cone snails, bugs, and spiders exhibiting different biological activities. They include ionic channel binding toxin (46-48), trypsin and Ramylase inhibitor (49), antimicrobial peptides $(10,11)$, and sweet taste suppressing peptide $(50,51)$. They all display the ICK motif of cysteines and a triple-stranded $\beta$-sheet; they differ by the length of loops and turns and also by the number of residues involved in the âstrands.

We searched the Protein Data Bank for peptides with structural similarities with Alo-3 using TOP (52), DALI (53), and SSM (54). Although TOP and SSM provided a large number of peptides with structural similarities, such as mammal defensins, plant and insect defensins, and scorpion toxins, in a first step, we restricted our comparison to peptides adopting a knottin fold. These structural neighbors include two antimicrobial peptides, PAFP-S (11) and tachystatin A (10), and a toxin from spider, ACTX-Hi:OB4219 (55). A structural alignment of these peptides with Alo-3 is presented in Figure $2 \mathrm{~B}$, and a ribbon representation of the four structures is shown in Figure 5. Among the three structural neighbors of Alo-3, the largest number of aligned residues, 27, is obtained with PAFPS (PDB code 1DKC) with an RMSD of $1.87 \AA$ for the CR atoms of the aligned residues. PAFP-S is an antifungal peptide isolated from the plant P. americana (26) active against some plant pathogen fungi such as Fusarium oxysporium, Fusarium graminearum, Alternaria tenuis, and Pyricularia oryzae. The RMSD between Alo-3 and ACTX-
Hi:OB4219 commonly called ACTX (PDB code 1KQH) is smaller (1.58 $\AA)$, but the number of aligned residues is only 25 . ACTX is one of the major components of the Australian spider Hadronyche infensa venom and shows structural analogies with $\mu$-agatoxins I and IV (55), two sodium channel inhibitors (56). The last peptide showing structural similarity to Alo-3 is tachystatin A (PDB code 1CIX). This peptide, isolated from the Japanese horseshoe crab (Tachypleus tridentatus) in the small granular hemocytes, inhibits the growth of Gram-negative bacteria, Gram-positive bacteria, and fungi (57). In this case the RMSD with Alo-3 is $1.83 \AA$ for 23 structurally aligned residues. The presence of a deletion in $\mathrm{T} 1$ and an insertion in the turn preceding the second strand B2, for ACTX and tachystatin A, leads to a smaller number of aligned residues than for PAFPS. The best structural alignments are obtained for strands B2 and B3 (RMSDs on the order of $1 \AA$ ) but also for the T2 turn. Actually, except for PAFP-S, where a â-turn is formed between the B1 and B2 strands, the $T 2$ turn is a long turn with the same overall shape on the structure of Alo-3, ACTX, and tachystatin A. In the same way, even if the RMSDs are larger for the T1 turn and for the B1 strand, there is still a rather good superposition of the backbones of the peptides in these regions. In fact, the only area showing large structural dissimilarities is loop L1, which adopts different conformations on each peptide (Figure 5, top). It should be noted that, except for Cys I, all cysteines are aligned (Figure 2B). This is in agreement with previous structural comparisons showing that the II-V and II-VI disulfide bridges are well preserved over all knottin structures while greater variability is observed for the I-IV bridge $(12,58-60)$.

We have extended our comparison to molecular properties related to the structure and of functional interest. For this purpose, we have calculated the electrostatic potentials for the four structurally related peptides and represented the distribution of hydrophilic and hydrophobic residues at the surface of the four molecules (Figure 5). The neurotoxin ACTX electrostatic isopotential contours present a patchwork of positive and negative zones, while the three antimicrobial peptides Alo-3, tachystatin A, and PAFP-S show large electropositive lobes. The largest ones appear at the bottom of the three molecules; the other side, at the top of the molecules, is generally more neutral. In Alo-3, the electropositive contours are due to the presence of positively charged residues in this area: the $\mathrm{N}$ terminal residue Cys1, Lys3, His23, Lys24, Arg34, Arg35, and Lys36. In tachystatin $A$ these large electropositive contours originate from a number of arginines, Arg25, Arg30, Arg40, and Arg43, clustered in this region of the molecule. Finally, in PAFP-S the N-terminal residue Ala1 and Lys5, Lys36, and Arg38 contribute to the electropositive lobes which extend toward the end of strand B1 with Arg9. As most antimicrobial peptides, Alo-3, tachystatin A, and PAFP-S are cationic, which may indicate that they act directly with the negatively charged bacterial or fungal membranes. However, as already observed for other antimicrobial peptides adopting a $C S \alpha \beta$ fold (20), the positive charges are not randomly distributed at the protein surface; instead, their specific arrangement leads to a large electropositive potential in a definite region of the molecule. Therefore, the cationic residues of Alo-3 involved in the formation of the positive contours play, most probably, a key role in its antifungal activity.

As previously discussed, the Alo-3 surface is essentially hydrophilic and there is only a small hydrophobic patch on the T2 turn due to Trp28, Val29, and Ala30. The other antifungal peptide, PAFP-S, appears also to be mainly hydrophilic with a small hydrophobic spot formed by Phe25, lle27 (second strand of the â-sheet), Ala28 (T2 turn), and Val34 (third strand of the â-sheet). The tachystatin A surface shows an intermediate hydrophobicity (green surface) with hydrophobic patches corresponding to the numerous aromatic residues: five tyrosines $(1,16,32,38$, and 44) and two phenylalanines ( 9 and 33). The surface of ACTX is the only one showing a hydrophobic face consisting of the beginning of the L1 loop (Trp12), the second strand of the $\beta$-sheet (Leu22), and the T2 
turn (lle26, Phe27, and Phe28). Therefore, the two purely antifungal peptides Alo-3 and PAFP-S are essentially hydrophilic. This pattern is however very different from that observed for other antifungal peptides with approximately the same size. For instance, antifungal insect defensins and several plant defensins adopting a $\operatorname{CS} \alpha \beta$ fold display a noticeable amphiphilicity of their molecular surface $(20$, $21,61)$. This probably means that all these peptides act by different mechanisms.

In summary, this study has established that Alo-3 adopts a knottin fold. The comparison of its structure with other structurally related peptides from other sources and with two analogues (Alo-1 and Alo2) allow a cationic pole that is presumably important for its antifungal activity to be delineated. This information may provide the molecular basis for the design of Alo analogues with an increased potency against Candida strains, constituting potential new drug therapies for the treatment of fungal diseases.

\section{Supporting information available}

$1 \mathrm{H}$ chemical shift table of Alo-3 $(293 \mathrm{~K}, \mathrm{pH} 5.2)$. This material is available free of charge via the Internet at http://pubs.acs.org.

\section{References}

1. Abi-Said, D., Anaissie, E., Uzun, O., Raad, I., Pinzcowski, H., and Vartivarian, S. (1997) Clin. Infect. Dis. 24, 1122-1128.

2. Barchiesi, F., Morbiducci, V., Ancarani, F., and Scalise, G. (1993) Eur. J. Epidemiol. 9, 455-456.

3. De Lucca, A. J., and Walsh, T. J. (1999) Antimicrob. Agents Chemother. 43, 1-11.

4. White, S. H., Wimley, W. C., and Selsted, M. E. (1995) Curr. Opin. Struct. Biol. 5, 521-527.

5. Thomma, B. P., Cammue, B. P., and Thevissen, K. (2003) Curr. Drug. Targets Infect. Disord. 3, 1-8.

6. Garcia-Olmedo, F., Molina, A., Alamillo, J. M., and Rodriguez-Palenzuela, P. (1998) Biopolymers 47, 479-491.

7. Tassin, S., Broekaert, W. F., Marion, D., Acland, D. P., Ptak, M., Vovelle, F., and Sodano, P. (1998) Biochemistry 37, 3623-3637.

8. Andersen, N. H., Cao, B., Rodriguez-Romero, A., and Arreguin, B. (1993) Biochemistry 32, 1407-1422.

9. De Bolle, M. F., Osborn, R. W., Goderis, I. J., Noe, L., Acland, D., Hart, C. A., Torrekens, S., Van Leuven, F., and Broekaert, W. F. (1996) Plant Mol. Biol. 31, 9931008.

10. Fujitani, N., Kawabata, S., Osaki, T., Kumaki, Y., Demura, M., Nitta, K., and Kawano, K. (2002) J. Biol. Chem. 277, 23651-23657.

11. Gao, G. H., Liu, W., Dai, J. X., Wang, J. F., Hu, Z., Zhang, Y., and Wang, D. C. (2001) Biochemistry 40, 10973-10978.

12. Pallaghy, P. K., Nielsen, K. J., Craik, D. J., and Norton, R. S. (1994) Protein Sci. 3, 1833-1839.

13. Norton, R. S., and Pallaghy, P. K. (1998) Toxicon 36, 1573-1583

14. Craik, D. J., Daly, N. L., and Waine, C. (2001) Toxicon 39, 43-60.

15. Bulet, P., Hetru, C., Dimarcq, J.-L., and Hoffman, D. (1999) DeV. Comp. Immunol. 23, 329-344

16. Fehlbaum, P., Bulet, P., Michaut, L., Lagueux, M., Broekaert, W. F., Hetru, C., and Hoffmann, J. A. (1994) J. Biol. Chem. 269, 33159-33163.

17. Lamberty, M., Ades, S., Uttenweiler-Joseph, S., Brookhart, G., Bushey, D., Hoffmann, J. A., and Bulet, P. (1999) J. Biol. Chem. 274, 9320-9326.

18. Lamberty, M., Zachary, D., Lanot, R., Bordereau, C., Robert, A., Hoffmann, J. A., and Bulet, P. (2001) J. Biol. Chem. 276, 4085-4092.

19. Landon, C., Sodano, P., Hetru, C., Hoffmann, J., and Ptak, M. (1997) Protein Sci. 6, 1878-1884.

20. Lamberty, M., Caille, A., Landon, C., Tassin-Moindrot, S., Hetru, C., Bulet, P., and Vovelle, F. (2001) Biochemistry 40, 11995-12003.

21. Da Silva, P., Jouvensal, L., Lamberty, M., Bulet, P., Caille, A., and Vovelle, F. (2003) Protein Sci. 12, 438-446.

22. Fehlbaum, P., Bulet, P., Chernysh, S., Briand, J. P., Roussel, J.P., Letellier, L., Hetru, C., and Hoffmann, J. A. (1996) Proc. Natl. Acad. Sci. U.S.A. 93, 1221-1225.

23. Mandard, N., Sodano, P., Labbe, H., Bonmatin, J. M., Bulet, P., Hetru, C., Ptak, M., and Vovelle, F. (1998) Eur. J. Biochem. 256, 404-410.

24. Michalowski, C. B., and Bohnert, H. J. EMBL/Genbank/DDBJ.

25. Terras, F. R., Eggermont, K., Kovaleva, V., Raikhel, N. V., Osborn, R. W., Kester, A., Rees, S. B., Torrekens, S., Van Leuven, F., Vanderleyden, J., and et al. (1995) Plant Cell 7, 573-588.

26. Shao, F., Hu, Z., Xiong, Y. M., Huang, Q. Z., WangCg, Zhu, R. H., and Wang, D. C. (1999) Biochim. Biophys. Acta 1430, 262-268.

27. Uttenweiler-Joseph, S., Moniatte, M., Lambert, J., Van Dorsselaer, A., and Bulet, P. (1997) Anal. Biochem. 247, 366-375.

28. Bulet, P., Cociancich, S., Reuland, M., Sauber, F., Bischoff, R., Hegy, G., Van Dorsselaer, A., Hetru, C., and Hoffmann, J. (1992) Eur. J. Biochem. 209, 977-984.
29. Rance, M., Sorensen, 0. W., Bodenhausen, G., Wagner, G., Ernst, R. R., and Wuthrich, K. (1983) Biochem. Biophys. Res. Commun. 117, 479-485.

30. Griesinger, C., Otting, G., Wu“thrich, K., and Ernst, R. R. (1988) J. Am. Chem. Soc. $110,7870-7872$.

31. Jeener, J., Meier, B. H., Bachmann, P., and Ernst, R. R. (1979) J. Chem. Phys. 71 4546-4553.

32. Piotto, M., Saudek, V., and Sklenar, V. (1992) J. Biomol. NMR 2, 661-5.

33. Delaglio, F., Grzesiek, S., Vuister, G. W., Zhu, G., Pfeifer, J., and Bax, A. (1995) J. Biomol. NMR 6, 277-293.

34. Johnson, B. A., and Blevins, R. A. (1994) J. Biomol. NMR 4, 603-614.

35. Wüthrich, K. (1986) NMR of proteins and nucleic acids, New York.

36. Linge, J. P., O'Donoghue, S. I., and Nilges, M. (2001) Methods Enzymol. 339, 71 90 .

37. Brünger, A. T., Adams, P. D., Clore, G. M., De Lano, W. L., Gros, P., GrosseKuntsleve, R. W., Jiang, J. S., Kuszewski, J., Nilges, M., Pannu, N. S., Read, R. J., Rice, L. M., Simonson, T.,and Warren, G. L. (1998) Acta Crystallogr., D: Biol. Crystallogr. 54, 905-921.

38. Linge, J. P., Williams, M. A., Spronk, C. A., Bonvin, A. M., and Nilges, M. (2003) Proteins 50, 496-506.

39. Koradi, R., Billeter, M., and Wuthrich, K. (1996) J. Mol. Graphics 14, 51-55.

40. Nicholls, A., and Honig, B. (1990) J. Comput. Chem. 12, 435-445.

41. Eisenberg, D., Schwarz, E., Komaromy, M., and Wall, R. (1984) J. Mol. Biol. 179, 125-142.

42. Nilges, M. (1993) Proteins 17, 297-309.

43. Boisbouvier, J., Blackledge, M., Sollier, A., and Marion, D. (2000) J. Biomol. NMR 16, 197-208.

44. Laskowski, R. A., Rullmannn, J. A., MacArthur, M. W., Kaptein, R., and Thornton, J. M. (1996) J. Biomol. NMR 8, 477-486.

45. Rees, D. C., and Lipscomb, W. N. (1982) J. Mol. Biol. 160, 475-498.

46. Bontems, F., Roumestand, C., Boyot, P., Gilquin, B., Doljansky, Y., Menez, A., and Toma, F. (1991) Eur. J. Biochem. 196, 19-28.

47. Savarin, P., Guenneugues, M., Gilquin, B., Lamthanh, H., Gasparini, S., Zinn-Justin, S., and Menez, A. (1998) Biochemistry 37, 5407-5416.

48. Bernard, C., Corzo, G., Mosbah, A., Nakajima, T., and Darbon, H. (2001) Biochemistry 40, 12795-12800.

49. Narasimhan, L., Singh, J., Humblet, C., Guruprasad, K., and Blundell, T. (1994) Nat. Struct. Biol. 1, 850-852.

50. Fletcher, J. I., Dingley, A. J., Smith, R., Connor, M., Christie, M. J., and King, G. F. (1999) Eur. J. Biochem. 264, 525-533.

51. Arai, K., Ishima, R., Morikawa, S., Miyasaka, A., Imoto, T., Yoshimura, S., Aimoto, S., and Akasaka, K. (1995) J. Biomol. NMR 5, 297-305.

52. Lu, G. (2000) J. Appl. Crystallogr. 33, 176-183.

53. Holm, L., and Sander, C. (1993) J. Mol. Biol. 233, 123-138.

54. Krissinel, E., and Henrick, K. EBI service for protein alignment and comparison in 3D, publicly available at http://www.ebi.ac.uk/msd-srv/ssm

55. Rosengren, K. J., Wilson, D., Daly, N. L., Alewood, P. F., and Craik, D. J. (2002) Biochemistry 41, 3294-3301.

56. Omecinsky, D. O., Holub, K. E., Adams, M. E., and Reily, M. D. (1996) Biochemistry $35,2836-2844$

57. Osaki, T., Omotezako, M., Nagayama, R., Hirata, M., Iwanaga, S., Kasahara, J., Hattori, J., Ito, I., Sugiyama, H., and Kawabata, S. (1999) J. Biol. Chem. 274, 26172-26178.

58. Heitz, A., Chiche, L., Le-Nguyen, D., and Castro, B. (1989) Biochemistry 28, 2392 2398.

59. Harrison, P. M., and Sternberg, M. J. (1996) J. Mol. Biol. 264, 603-623.

60. Wang, X., Connor, M., Smith, R., Maciejewski, M. W., Howden, M. E., Nicholson, G. M., Christie, M. J., and King, G. F. (2000) Nat. Struct. Biol. 7, 505-513.

61. Landon, C., Pajon, A., Vovelle, F., and Sodano, P. (2000) J. Pept. Res. 56, 231-238.

62. Cammue, B. P., De Bolle, M. F., Terras, F. R., Proost, P., Van Damme, J., Rees, S. B., Vanderleyden, J., and Broekaert, W. F. (1992) J. Biol. Chem. 267, 2228-2233. 